\title{
Financial Analysis of Crop-Livestock-Forestry Systems in Goias, Brazil
}

\author{
Juliana Baldan Costa Neves Araújo ${ }^{1}$, Álvaro Nogueira de Souza ${ }^{1}$, Maísa Santos Joaquim ${ }^{2}$, Ilvan Medeiros Lustosa \\ Junior $^{3}$, Maisa Isabela Rodrigues ${ }^{1}$ and Lucas Francisco de Dominicis ${ }^{1}$ \\ 1. Department of Forest Engineering, Faculty of Technology, University of Brasilia, Brasilia 70910-900, DF, Brazil \\ 2. Faculty of Agronomy and Veterinary Medicine, University of Brasilia, Brasilia 70910-900, DF, Brazil \\ 3. Federal Institute of Brasília-Planaltina Campus, DF-128 Highway, km 21, Planaltina 73380-900 DF, Brazil
}

\begin{abstract}
Integration system is used to denote practices that combine systematic use of the land and technologies, in which forest species are used in conjunction with herbaceous plants and/or animals respecting a spatial or temporal arrangement. Knowing that this type of production seeks to balance ecological and economic factors, it is important to understand the financial benefits and risks involved in this production. Financial analysis, therefore, acts as an important analysis tool to foster this type of activity. The paper aimed to conduct analysis of investment risk of a crop-livestock-forestry system deployed in Brazil, comparing two different production scenarios, scenario I with 17 ha and scenario II with 25 ha. The risk analysis was performed using the Monte Carlo method and sensitivity analysis (by varying the factors: the discount rate, productivity and price). A cash flow was elaborated based on annual cost and revenues data of the agricultural crops (corn and soybeans), livestock and eucalyptus, using an interest rate of $6 \%$ per year. The results indicated that the optimal age for cutting the eucalyptus was at seven years on both scenarios; scenario I had better return on investment using deterministic and probabilistic methods; scenario I presents higher investments risks; there is a negative relation between discount rate and annualized net present value (ANPV); increased productivity of crops provides greater profitability to the system; there has been an increase in the economic viability of the system, as value has been added to the products. Monte Carlo method and the sensitivity analysis showed to be an appropriate tool to analyze the risk of crop-livestock-forestry systems, making it possible to foresee how the project will respond to possible scenarios.
\end{abstract}

Key words: Agroforestry system, risk, Monte Carlo method and sensitivity analysis.

\section{Introduction}

Brazil is a country with great agricultural potential and contributes to food production. However, it is known that a large part of the arable land is with the productive capacity at the limit. And to warm up agricultural production in the country there are alternatives such as intensifying the use of chemicals and exploring new areas [1].

Like agriculture, livestock farming also begins to find barriers to development. Intensified in the 1960s by the Brazilian government, extensive farming has been causing systematic disturbances over time in the

Corresponding author: Juliana Baldan Costa Neves Araújo, MSc., research fields: forest sciences, integrated systems, financial analysis and forest economy. structure and function of several ecosystems and abruptly altering the landscape [2].

The forestry sector behaves in some respects in the same way, because due to the greater demand for its products and technological evolution, the forestry activity has been dominated by standardized and simplified monoculture systems. In addition, with the mechanized soil management, the use of chemicals and irrigation, the activities started to be intensified and dissociated [3].

At the end of the 1970s, monoculture models, predominant in the Center-South, Southeast and, to a lesser extent, in Northern Brazil, began to show production and price instability due to market risks, phytosanitary and harvest problems [4]. Demanding from the sector changes in production to meet the new 
needs of the market.

According to Bulhões [5], the process of producing novelties and innovations in agriculture is contextual and continuous. And among the several novelties, one that calls attention is the set of different forms of management of crop-livestock-forest integration systems and their complexity.

The integration systems align livestock, crop and forestry activities simultaneously [6]. This form of production has received great attention as an alternative form of economic support to small producers and maintenance of ecosystem functions [7].

The use of integrated systems has been indicated to develop the rural sector by providing greater income generation, rural poverty reduction and protection of the environment. Despite this, incentives such as public policies in the form of institutional support, credit, tree planting and other incentives [8] are needed for the farmer to adopt such a productive system. And for that, it is important that the producer knows clearly the financial benefits of this activity.

In Brazil, these systems are characterized as a production system of political importance, mainly as a strategy for sustainable development in endangered ecosystems, a trend that follows the line of internationally financed programs offered by the World Bank [5].

Like other forest investments, the decision-making process of crop-livestock-forestry systems becomes complex because they have a long production cycle. It also considers the economic and financial aspects, the constraints of the factors of production and the risks involved in the production process. In addition, investments in the forestry sector require a significant amount of capital, which will be immobilized over a long period. And these are the two variables that most influence decision making in a forest enterprise [9].

In this type of system there are several stages in its production process, thus different agricultural and forestry practices are necessary for the management. Therefore, the financial analysis becomes complex because it involves several technical and cost variables [10].

Varela and Santana [4] affirm that economic fundamentals are an essential component in the choice and decision process, especially for the adoption of production systems considered as preservationists, or that involve adequate forest and soil management and use, as is the case of crop-livestock-forestry systems.

Because it is an important alternative to the traditional production model and requires rigorous planning, studies on these types of production are fundamental tools to encourage the use of this system, increasing the profitability of the system and reducing possible risks. In addition, because there are few scientific studies that address the risks of this productive system, it becomes evident for the importance of studies on risk assessment in agroforestry ventures.

This study aimed to analyze the investment risk using Monte Carlo method and sensitivity analysis of a crop-livestock-forestry integrated system in two different production scenarios and to indicate the production scenario with the highest financial return.

\section{Materials and Methods}

\subsection{Location and Characterization of the Study Area}

The data used for integration system risk analysis were collected at the crop-livestock-forestry integrated system located in the state of Goias-Brazil. The farm has two production glebes, scenario I with 17 ha and scenario II with 25 ha.

The system under study was implanted as follows: (1) soybean and eucalyptus are planted in the first year, being considered zero year of the system; (2) the following year (year 1), after the soybean harvest, maize intercropped with the Brachiaria is planted. And when the maize is harvested, the pasture is already formed and can be used.

The tree species selected were Eucalyptus grandis and E. urophylla. The soybean variety used was 
BRS-GO 8360, maize varieties were BRS 1030 and 1035. Brachiaria was used to pasture for the cattle and the introduced animals present an average weight of $242 \mathrm{~kg}$.

For the application of the system risk analysis method, two production scenarios, already deployed in the study area, were compared (Table 1).

The occupation of the area in the first scenario is $62.5 \%$ crop and $37.5 \%$ forest, having a density of 500 trees per hectare. While in the second scenario, there is $66 \%$ of the area occupied by agriculture and $34 \%$ with forest, with 430 trees per hectare.

The characterization of the productivity of each crop in their respective scenarios is presented in Table 2.

\subsection{Characterization of the Database}

The data for applying the study methodologies were obtained with the producer who implanted the crop-livestock-forestry system in his property. And the database is composed of cost data (Table 3 ), revenue and production of activities performed on the property.

The selling prices of the products (Table 4) from the systems were quoted on the Agrolink website, with the average prices in March and April 2014 for the state of Goias.

With the cost data for implementation and maintenance of the crop-livestock-forestry system, shown above, and the revenue data (sales of soy, maize, livestock and standing timber), the cash flows were constructed for each production scenario.

The discount rate used for the calculations was $6 \%$ per year and it represents the opportunity cost of the rural producer when applying capital in the crop-livestock-forest integration project.

Table 1 Characterization of the scenarios analyzed.

\begin{tabular}{lll}
\hline Feature & Scenario I & Scenario II \\
\hline Rows of eucalyptus & 3 & 4 \\
Eucalyptus spacing & $3 \mathrm{~m} \times 3 \mathrm{~m}$ & $3 \mathrm{~m} \times 3 \mathrm{~m}$ \\
Space between crop/livestock & $14 \mathrm{~m}$ & $22 \mathrm{~m}$ \\
\hline
\end{tabular}

Table 2 Average productivity per hectare of the crops.

\begin{tabular}{llll}
\hline \multirow{2}{*}{ Scenario } & \multicolumn{3}{c}{ Productivity } \\
\cline { 2 - 4 } & Soy (sack) & Maize $($ sack $)$ & Livestock $(\mathrm{kg})$ \\
\hline I & 33 & 67 & 270 \\
II & 31 & 70 & 270 \\
\hline
\end{tabular}

$1 \mathrm{sack}=60 \mathrm{~kg}$.

Table 3 Description of crop-livestock-forestry system implementation and maintenance costs in scenarios I and II.

\begin{tabular}{llll}
\hline Costs & Year & Scenario I & Scenario II \\
\cline { 3 - 4 } & & Cost (R\$/ha) & Cost (R\$/ha) \\
\hline Soy plantation & 0 & 806.16 & 908.18 \\
Soy harvest & 0 & 102.96 & 96.72 \\
Eucalyptus implantation & 0 & 601.23 & 594.32 \\
Maize and Brachiaria plantation & 1 & 811.19 & 856.61 \\
Maize harvest & 1 & 118.71 & 120.782 \\
Eucalyptus maintenance & 1 & 185.25 & 165.44 \\
Introduction of cattle & 2 & $1,692.00$ & $1,692.00$ \\
Pasture maintenance & 2 to 12 & 360.00 & 360.00 \\
Eucalyptus maintenance & 2 to 12 & 163.00 & 163.00 \\
Cattle acquisition & 3 to 12 & 564.00 & 564.00 \\
Land cost of opportunity & 1 to 12 & 420.00 & 420.00 \\
\hline
\end{tabular}

$1 \mathrm{US} \$=\mathrm{R} \$ 3.80$ in July, 2018. 
Table 4 Prices of crop-livestock-forestry system products.

\begin{tabular}{lll}
\hline Product & Average price $(\mathrm{R} \$)$ & Unit \\
\hline Soy & 59.77 & Sack \\
Maize & 24.19 & Sack \\
Cattle & 115.65 & $\mathrm{~kg}$ \\
Eucalyptus & 35.00 & $\mathrm{~m}^{3}$ \\
\hline
\end{tabular}

$1 \mathrm{US} \$=\mathrm{R} \$ 3.80$ in July, 2018; 1 sack $=60 \mathrm{~kg}$.

\subsection{Economic Rotation}

To estimate wood production each year, the Gompertz function was used for the ages of 1-12 years (for each production scenario), according to the following formula [11]:

$$
Y=K\left(1-e^{-a e^{b I}}\right)
$$

where $Y=$ production of wood in meters $\mathrm{m}^{3} / \mathrm{ha} ; K=$ coefficient (scenario $\mathrm{I}=200$ and scenario $\mathrm{II}=170$ ); $a=$ $0.061 ; b=0.045 ; I=$ settlement age (months).

Then, the annual average increment (IMA), described as the average rate of increase in production since the implementation of the stands up to a certain age, was calculated, and the current annual increase (ICA), which corresponds to the increase in production in one year [12].

$$
\mathrm{IMA}=\frac{V_{i}}{I_{i}}
$$

where IMA $=$ annual average increment $\left(\mathrm{m}^{3} / \mathrm{ha} /\right.$ year $)$; $V_{i}=$ volume at age $i ; I=$ age (years).

$$
\mathrm{ICA}=V_{i+1}-V_{i}
$$

where ICA = current annual increase $\left(\mathrm{m}^{3} / \mathrm{ha}\right) ; V_{i+1}=$ volume of age $i+1\left(\mathrm{~m}^{3}\right) ; V_{i}=$ volume at age $i\left(\mathrm{~m}^{3}\right)$.

Using the factors, IMA, ICA and the optimum economic rotation, makes it possible an evaluation of the investment criteria, economic feasibility of a forestry project, and the best time for the rotation of the stand [13].

\subsection{Methods of Analysis}

For the application of the Monte Carlo method, first, some economic parameters were calculated, such as net present value (NPV) and annualized net present value (ANPV).
The NPV of a project is defined as the algebraic sum of the discounted values of the cash flow associated with it [14]. The formula used for the calculation was:

$$
\mathrm{NPV}=\sum_{j=0}^{n} R j(1+i)^{-j}-\sum_{j=0}^{n} C j(1+i)^{-j}
$$

where $C j=$ cost at the end of the period of time considered; $R j=$ revenue at the end of the period of time considered; $i=$ discount rate; $n=$ duration of the project (years).

The ANPV transforms the current value of the project (NPV) into periodic and continuous revenues and costs, becoming equivalent to the current value of the project while the project as it is implemented and realized. The formula used for this calculation was presented by Rezende and Oliveira [14]:

$$
\mathrm{ANPV}=\frac{\mathrm{NPV} \times\left[(1+i)^{t}-1\right] \times(1+i)^{n t}}{(1+i)^{n t}-1}
$$

where $n=$ duration of the project (years); $t=$ number of capitalization periods (in the case study, $t=1$ ).

If the ANPV value is positive, the project can be considered economically feasible, periodic benefits are higher than periodic costs [14].

The ANPV should be used, according to Rezende and Oliveira [14], this method allows the comparison of projects with different durations or useful lives, and the NPV method would not be a good alternative for the analysis of this study.

\subsubsection{Monte Carlo Method}

First, the historical series of the desired variables, prices of the soybean sack, the maize sack, value of the cattle and the cubic meter standing of eucalyptus, used by Joaquim [15] were updated and adapted. The period of the series comprises between January 1998 and 
December 2013. The updated data were obtained from the Agrolink website, the Institute of Agricultural Economics (IEA) and the Institute of Applied Economic Research (IPEA), following the methodology proposed by Joaquim [15].

Then, all prices were deflated by the General Price Index-Internal Availability (IGP-DI). The index is a synthetic measure of national inflation structured to capture the general movement of prices through research in coverage areas-from agricultural raw material prices to final goods and services prices [16]. The historical series of the IGP-DI index was obtained from the Fundação Getúlio Vargas/Brazilian Institute of Economics (FGV/IBRE) website.

Deflation was performed as follows: the first month of the series (in the case, January 1998) was considered the base year, being equaled to 100 , and then the formula was applied to calculate the corrected IGP-DI:

$$
\mathrm{IGP}-\mathrm{DI} \mathrm{corrected}=\frac{\mathrm{IGP}-\mathrm{DI}_{i}}{\mathrm{IGP}-\mathrm{DI} I_{i-1}} \times \text { Base }
$$

where IGP-DI ${ }_{i}=$ accumulated for the current month; $\mathrm{IGP}-\mathrm{DI}_{i-1}=$ accumulated from the previous month; Base $=100$.

After calculating the corrected IGP-DI, it was possible to determine the new deflator value, by means of the following calculation:

$$
\text { Deflator }=\frac{\text { IGP-DI }_{\text {corrected }(i)}}{\text { IGP-DI }_{\text {corrected }(i-1)}}
$$

where corrected IGP-DI $\mathrm{corrected}(i)_{\text {I }}$ IGP-DI corrected for the current month; fixed IGP-DI corrected $(i-1)=$ fixed IGP-DI of the previous month.

Taking the variables to be analyzed, the means and standard deviations for each variable were calculated. With these parameters, Monte Carlo method simulations were performed. To do this, 10,000 random numbers (in Microsoft Excel 2010) were generated for all variables under analysis. Considering the mean and standard deviation of each variable, such random numbers should have a normal distribution [15, 17]. In this way, the histogram was constructed to analyze the behavior of such variables.

When the histograms were constructed, it was possible to obtain the probability of occurrence of the highest frequency value for the prices of each product of the system, at the point where the frequency curve intersects the lower limit of the cumulative frequency curve. According to Coelho Júnior [18], the cumulative frequency distribution provides the risk for each of the activities. And with these values new cash flows were set up for the scenarios analyzed.

The Monte Carlo methodology was also used with the output variables of the analyzed systems, NPV and ANPV, for more accurate risk analysis and to help in decision making.

The last simulation was performed using: economic indicators, percentiles (responsible for identifying the probability of reaching an outcome associated with a level of probability), standard deviation (related to the risk level and the dispersion of the possible results) and coefficient of variation (measures the risk and return variations of the sample) [19].

The criterion for systemic risk classification was used according to Silva and Cunha [19], where coefficient of variation lower than $10 \%$ indicates low risk, between $10 \%$ and $20 \%$ indicates average risk, between $20 \%$ and $30 \%$ indicates high risk and coefficient higher that 30\% indicates very high risk.

\subsubsection{Sensitivity Analysis}

The sensitivity analysis was applied, according to methodology used by Souza [20] and Souza et al. [21], to changing discount rate, price (wood, cattle, soy and maize) and productivity. In this way, it was possible to analyze the ANPV sensibility against these variations.

The discount rates applied in the test were $6 \%, 8 \%$, $12 \%$ and $14 \%$ per year. These rates were applied since they are considered the values most used in forestry projects [19].

According to the methodology proposed by Richetti [22], the analysis of prices was made considering conditions of greater favorability and lower favorability. For wood, livestock, soybean and maize 
prices, the maximum and minimum values of the historical series of each crop were used.

For the crop productivity, variations of $10 \%$ and $20 \%$ were used, for more and for less [23].

After making the variations provided for in the methodology, values from one to four were assigned according to the importance of the impact on the ANPV. To do so, a value of one is assigned for higher percentage variation of ANPV and of four for lower percentage variation of ANPV.

\section{Results and Discussion}

\subsection{Economic Rotation}

With the Gompertz equation it was possible to estimate the production of wood for each year. And these values determine the average annual increase and annual current increase for the respective ages. These calculations were performed for production scenarios I and II (Table 5).

According to the results obtained, and knowing that the maximum IMA determines the best cut age [12], the ideal cut age observed for both scenarios I and II was seven years.

\subsection{Cash Flow}

With the productivity data for all crops performed in the crop-livestock-forestry systems and the cost and revenue data for both production scenarios, it was possible to build cash flow. Thus, to calculate the NPV and ANPV, make possible the determination of the eucalyptus cutting year, as well as the scenario that presented higher profitability (Table 6).

Table 5 Results for volume, annual average increment (IMA) and current annual increase (ICA) of scenarios I and II.

\begin{tabular}{lllllll}
\hline \multirow{2}{*}{ Age (year) } & \multicolumn{3}{c}{ Scenario I } & \multicolumn{3}{l}{ Scenario II } \\
\cline { 2 - 7 } & Volume $\left(\mathrm{m}^{3} / \mathrm{ha} /\right.$ year $)$ & $\mathrm{IMA}\left(\mathrm{m}^{3}\right)$ & $\mathrm{ICA}\left(\mathrm{m}^{3}\right)$ & Volume $\left(\mathrm{m}^{3} / \mathrm{ha} /\right.$ year $)$ & IMA $\left(\mathrm{m}^{3}\right)$ & ICA $\left(\mathrm{m}^{3}\right)$ \\
\hline 1 & 19.88 & - & - & 16.90 & - & - \\
2 & 32.88 & 16.44 & 13.01 & 27.95 & 13.98 & 11.06 \\
3 & 53.05 & 17.68 & 20.17 & 45.09 & 15.03 & 17.14 \\
4 & 82.15 & 20.54 & 29.10 & 69.83 & 17.46 & 24.74 \\
5 & 119.31 & 23.86 & 37.15 & 101.41 & 20.28 & 31.58 \\
6 & 157.87 & 26.31 & 38.56 & 134.19 & 22.36 & 32.78 \\
7 & 186.19 & 26.60 & 28.32 & 158.26 & 22.61 & 24.07 \\
8 & 197.96 & 24.75 & 11.77 & 168.27 & 21.03 & 10.01 \\
9 & 199.92 & 22.21 & 1.96 & 169.94 & 18.88 & 1.67 \\
10 & 200.00 & 20.00 & 0.08 & 170.00 & 17.00 & 0.06 \\
11 & 200.00 & 18.18 & 0.00 & 170.00 & 15.45 & 0.00 \\
12 & 200.00 & 16.67 & 0.00 & 170.00 & 14.17 & 0.00 \\
\hline
\end{tabular}

Table 6 Net present value (NPV) and annualized net present value (ANPV) calculated for scenarios I and II.

\begin{tabular}{lllll}
\hline \multirow{2}{*}{ Year } & \multicolumn{3}{c}{ Scenario I } & \multicolumn{2}{c}{ Scenario II } \\
\cline { 2 - 5 } & NPV $(\mathrm{R} \$ / \mathrm{ha})$ & ANPV $(\mathrm{R} \$ / \mathrm{ha})$ & $2,337.987$ & ANPV $(\mathrm{R} \$ / \mathrm{ha})$ \\
\hline 4 & $2,845.689$ & 821.242 & $3,483.795$ & 677.987 \\
5 & $4,117.914$ & 977.578 & $4,547.574$ & 827.040 \\
6 & $5,297.923$ & $1,077.400$ & $5,302.655$ & 924.807 \\
7 & $6,118.805$ & $1,096.092$ & $5,674.485$ & 949.891 \\
8 & $6,492.622$ & $1,045.545$ & $5,840.031$ & 913.796 \\
9 & $6,627.352$ & 974.368 & $5,962.934$ & 858.614 \\
10 & $6,715.313$ & 912.396 & $6,077.620$ & 810.172 \\
11 & $6,796.812$ & 861.788 & $6,185.810$ & 770.599 \\
12 & $3,873.693$ & 819.874 & 737.825 \\
\hline
\end{tabular}

$1 \mathrm{US} \$=\mathrm{R} \$ 3.80$ in July, 2018. 
As in studies by Souza et al. [24], Arco-Verde [25] and Bramucci [23], in the first three years of production, the annual balance is negative, showing that costs are higher than revenues. From the 4th year onwards, there is a positive cash flow. Therefore, it is important to consider the integration system as a whole, as well as the benefits provided by the annual activities.

The year with the highest ANPV represents the period where the producer will obtain the highest return and also represents the best scenario for cutting the eucalyptus, that is, the ideal age of cutting the eucalyptus in these production scenarios occurred at the age of seven.

This result is in accordance with the work of Bramucci [26], Dias et al. [27], Rezende and Oliveira [28], Soares [29], Souza et al. [21], Souza et al. [24] and Wilcken et al. [30], where the eucalyptus cut occurs on average between seven and 12 years.

Analyzing the results and using the same criteria as the authors of Refs. [10, 23], it is concluded that the two scenarios are economically viable, and that scenario I is the best arrangement to be used since it represents a greater return to the producer.

According to the authors who studied the financial viability of integrated coffee and marrango tree systems in Indonesia [31], the positive result of the financial viability is an interesting auxiliary tool to demonstrate to farmers the financial benefits of agroforestry and to foster the activity.

As in the study of integration systems in Germany [32], crop integration systems are financially viable alternatives. The authors also point out that the greater participation of the environmentally conscious consumer market may be responsible for increasing the financial viability of these systems.

\subsection{Risk Analysis—Monte Carlo Method}

In order to generate the random numbers required for the Monte Carlo method, parameters-mean, variance and standard deviation - were calculated for the variables under analysis, obeying the normality criteria (Table 7).

With this, it was possible to verify the probability of occurrence of the prices of the products of the system. The following histograms show the results of the Monte Carlo method, in the analysis of historical series of prices of crop-livestock-forestry system products.

Following the parameters established by the proposed methodology, in the histograms it is possible to observe the random values generated based on the variables analyzed, on the $\mathrm{x}$-axis, and the frequency of zero of these prices, on the y-axis.

According to Fig. 1, the probability distribution of maize price is likely to be $76 \%$ of the price to be close to $\mathrm{R} \$ 45.37$. For cattle the probability, it is $79 \%$ of the price to be close to $\mathrm{R} \$ 84.96$. For eucalyptus, there is a probability that $77 \%$ of the price will be close to $\mathrm{R} \$ 50.57$. And for soybeans there is a probability that $73 \%$ of the price will be close to $\mathrm{R} \$ 21.62$.

After determining the prices and their probability of occurrence, a new cash flow was set up and new NPV and ANPV values were calculated (Table 8).

In the two scenarios analyzed there was no change in the optimal cutting age of eucalyptus after the Monte Carlo method and composition of the new cash flow. And as determined by the traditional method, the methodology confirms that scenario I presents greater profitability for the producer, obtaining a higher value of ANPV.

Table 7 Parameters used for the Monte Carlo method.

\begin{tabular}{llll}
\hline \multirow{2}{*}{ Product } & \multicolumn{3}{c}{ Parameters } \\
\cline { 2 - 4 } & Mean & Variance & Standard deviation \\
\hline Soy & 36.64 & 192.30 & 13.87 \\
Maize & 17.70 & 36.58 & 6.05 \\
Cattle & 63.92 & 547.43 & 23.40 \\
Eucalyptus & 42.18 & 149.83 & 12.24 \\
\hline
\end{tabular}


(a)

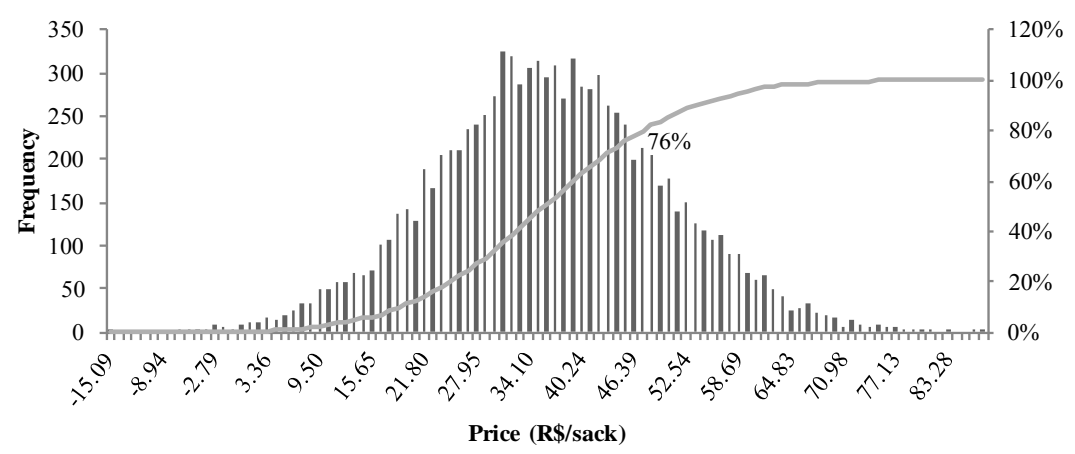

(b)

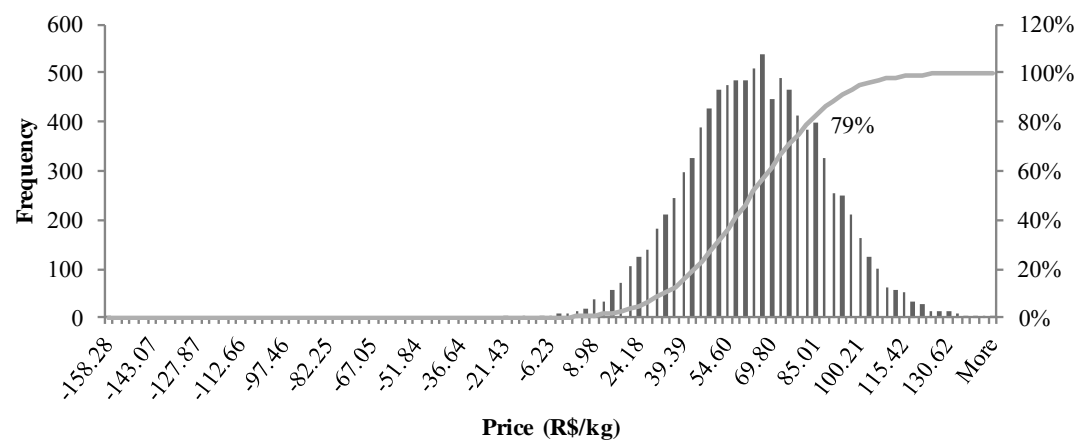

(c)

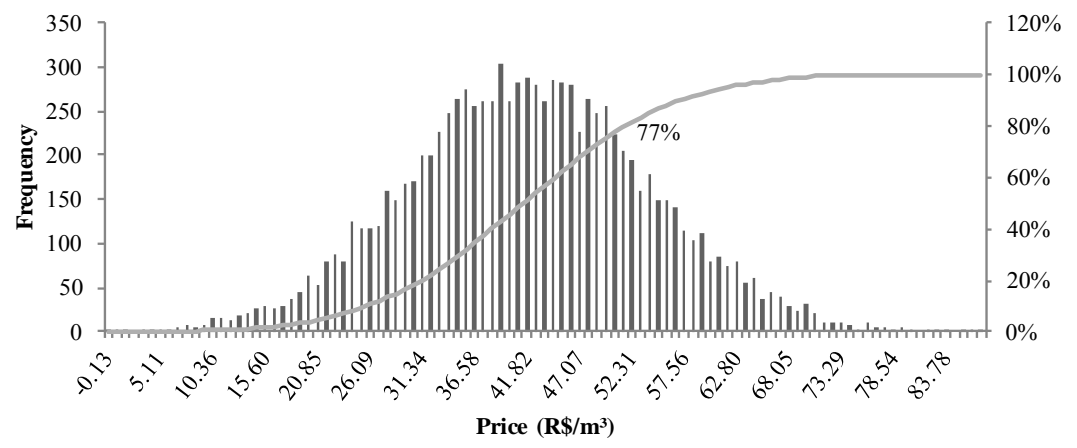

(d)

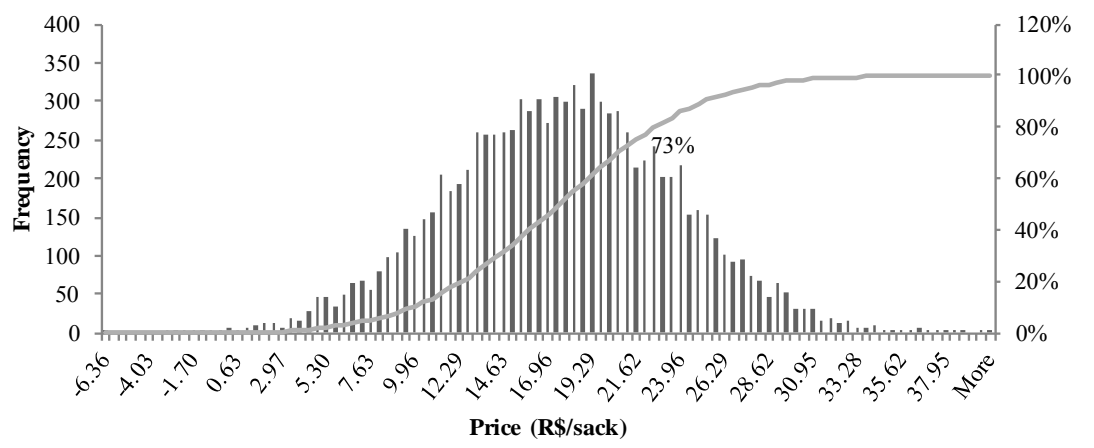

Fig. 1 Histograms of crop prices: (a) maize, (b) cattle, (c) eucalyptus and (d) soybeans. $1 \mathrm{US} \$=\mathrm{R} \$ 3.80$ in July, 2018. 
Table 8 Values of NPV and ANPV after application of the Monte Carlo method, for scenarios I and II.

\begin{tabular}{lllll}
\hline \multirow{2}{*}{ Year } & \multicolumn{3}{c}{ Scenario I } & \multicolumn{2}{c}{ Scenario II } \\
\cline { 2 - 5 } & NPV (R\$/ha) & ANPV (R\$/ha) & NPV (R\$/ha) & ANPV (R\$/ha) \\
\hline 4 & $2,177.346$ & 628.364 & $1,505.026$ & 434.338 \\
6 & $3,481.208$ & 826.426 & $2,613.990$ & 620.552 \\
7 & $4,680.119$ & 951.761 & $3,633.708$ & 738.960 \\
8 & $5,360.472$ & 960.248 & $4,212.614$ & 754.627 \\
9 & $5,384.704$ & 867.131 & $4,233.783$ & 681.791 \\
10 & $5,071.583$ & 745.635 & $3,968.170$ & 583.409 \\
11 & $4,715.837$ & 640.731 & $3,666.296$ & 498.132 \\
12 & $4,377.943$ & 555.092 & $3,379.566$ & 428.505 \\
\hline
\end{tabular}

$1 \mathrm{US} \$=\mathrm{R} \$ 3.80$ in July, 2018.

Table 9 Parameters used for Monte Carlo method.

\begin{tabular}{lllll}
\hline \multirow{2}{*}{ Parameters } & \multicolumn{3}{c}{ Scenario I } & \multicolumn{2}{c}{ Scenario II } \\
\cline { 2 - 5 } & NPV $(\mathrm{R} \$ / \mathrm{ha})$ & ANPV $(\mathrm{R} \$ / \mathrm{ha})$ & $\mathrm{NPV}(\mathrm{R} \$ / \mathrm{ha})$ & ANPV $(\mathrm{R} \$ / \mathrm{ha})$ \\
\hline Average & $3,983.99$ & 713.089 & $3,432.601$ & 592.46 \\
Variance & $9,083,868$ & 203,602 & $7,550,514$ & $194,491.3$ \\
Standard deviation & $3,013.95$ & 451.23 & $2,747.82$ & 441.0117 \\
\hline
\end{tabular}

$1 \mathrm{US} \$=\mathrm{R} \$ 3.80$ in July, 2018.

It can be seen that, as in the study by Silva [2], the values for the ANPV indicator are lower when the risk is taken into consideration in the analysis indicating the importance of the Monte Carlo method, since it can portray the real financial return of the venture in the face of uncertainties, such as price.

As in the analysis of the historical series of prices, in order to generate the random numbers, parameters of the variables NPV and ANPV were calculated (Table 9).

The following histograms (Fig. 2) present the probabilities of occurrence of the economic indicators, NPV and ANPV, for both production scenarios.

There is a $78.96 \%$ probability of NPV occurring equal to $\mathrm{R} \$ 6,396.01 / \mathrm{ha}$ and $76.22 \%$ of ANPV occurring equal to $R \$ 1,026.09 / \mathrm{ha}$, in scenario I of production. For scenario II, there is a probability of $78.6 \%$ of NPV equal to R $\$ 5,656.02 /$ ha and $87.33 \%$ of ANPV equal to R $\$ 1,090.62 / \mathrm{ha}$.

In the percentiles analysis (Table 10), it can be inferred that there is a probability of 0 to $10 \%$, for scenarios I and II, of NPV and ANPV incinerators with negative values, which would make the project unfeasible.

The values obtained in the analysis, indicate high project viability and good probability of occurrence of economically advantageous scenarios to the project. However, the coefficient of variation obtained in the risk analysis shows that the possible values of the economic indicators are very dispersed in the sample, suggesting that there is a high investment risk in the integration projects.

Coelho Júnior et al. [18], emphasize that the precision of the decision-making is related to the manager's knowledge and domain of the circumstances of the investment. If, based on the Monte Carlo method, the decisions taken are more than $50 \%$ likely to be correct, then these decisions will be superior to those made based on traditional methods alone. As for all variables analyzed, the probability of occurrence was higher than $50 \%$, it can be said that this production has, from an economic point of view, good attractiveness.

When comparing the results of the traditional method with the results of the probabilistic method, it is noticed that the Monte Carlo methodology is an interesting tool to aid in decision making, and can be a 
(a)

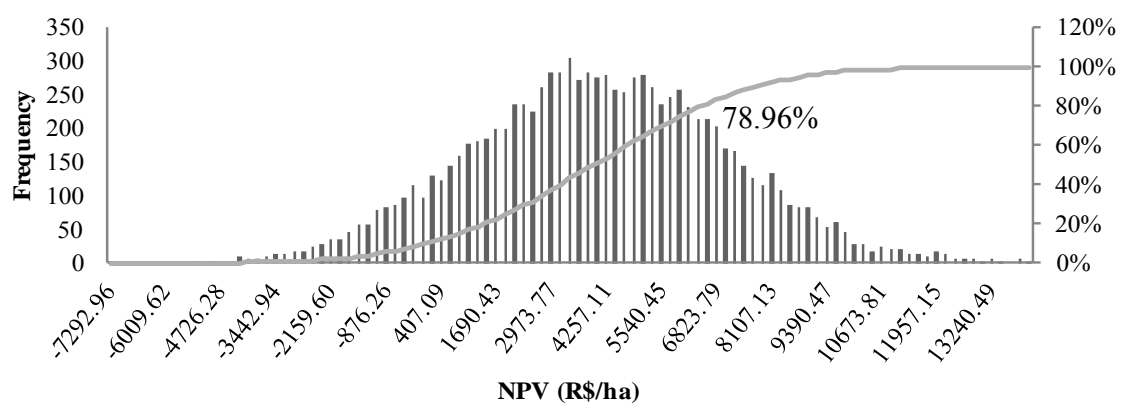

(b)

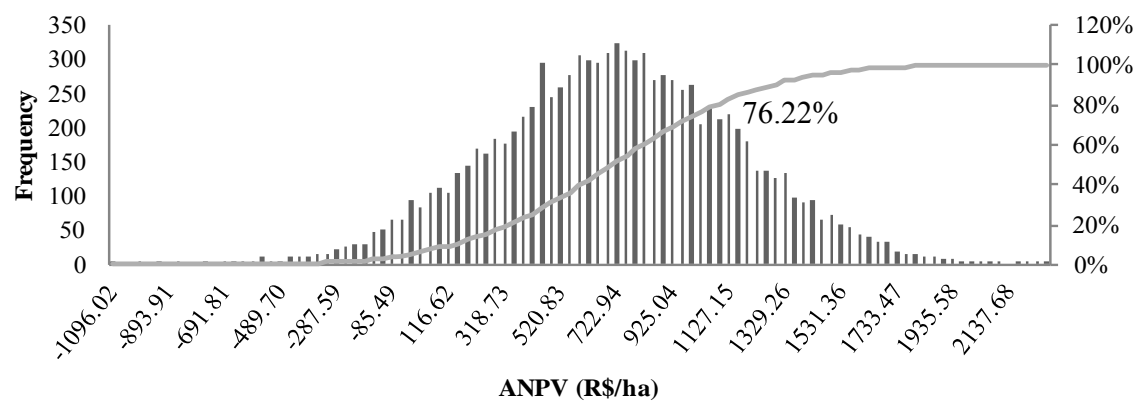

(c)

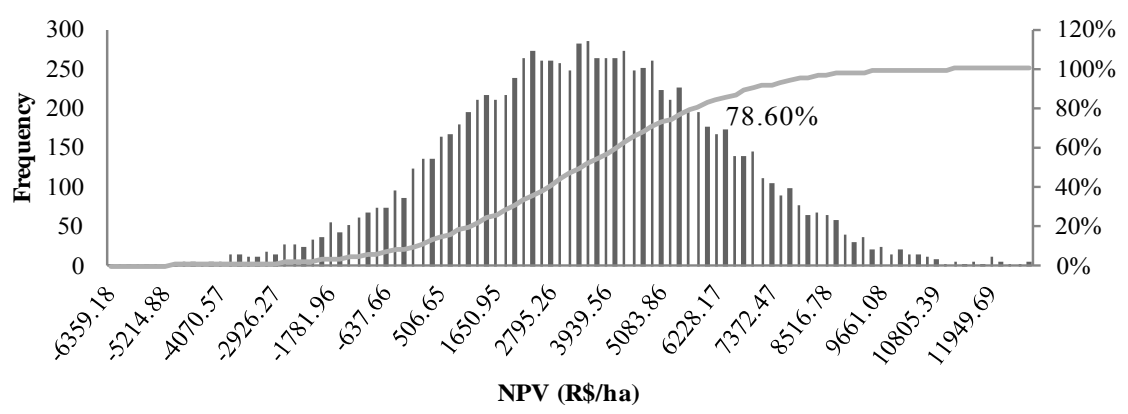

(d)

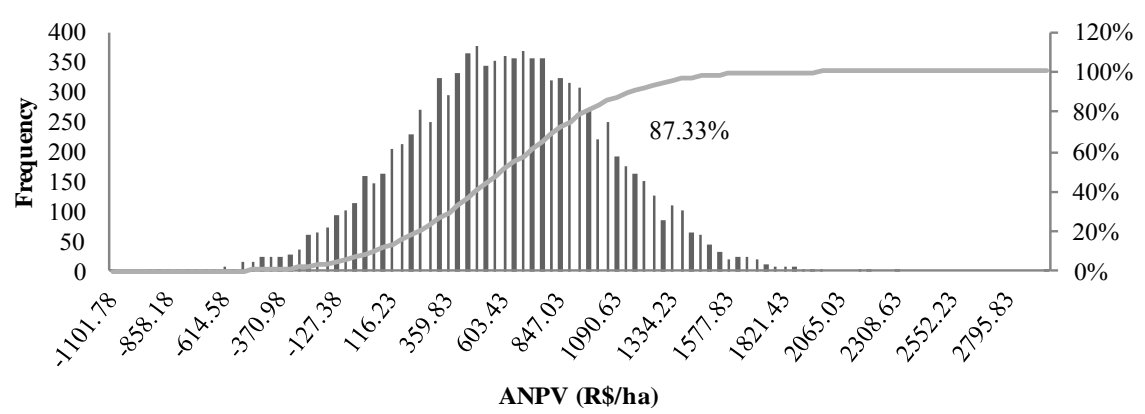

Frequency Cumulative (\%)

Fig. 2 Histograms of economic indicators: (a) net present value (NPV) of scenario I, (b) annualized net present value (ANPV) of scenario I, (c) NPV of scenario II and (d) ANPV of scenario II.

$1 \mathrm{US} \$=\mathrm{R} \$ 3.80$ in July, 2018. 
Table 10 Statistics for the output variables for the integration system.

\begin{tabular}{lllll}
\hline \multirow{2}{*}{ Statistics } & \multicolumn{2}{c}{ Scenario I } & Scenario II \\
\cline { 2 - 5 } & NPV (R $/$ ha $)$ & ANPV $(\mathrm{R} \$ / \mathrm{ha})$ & $-6,359.18$ & $-1,101.78$ \\
\hline Minimum & $-7,292.96$ & $-1,096.02$ & $12,712.56$ & $2,958.231$ \\
Maximum & $14,096.05$ & $2,272.42$ & $3,445.212$ & 591.6188 \\
Average & $3,972.12$ & 706.1482 & $2,777.973$ & 438.7421 \\
Standard deviation & $3,012.026$ & 444.9551 & $1,167.735$ & $1,097.228$ \\
Mode & $2,047.128$ & 755.2797 & 80.63288 & 74.15959 \\
Coefficient of variation & 75.82917 & 63.01157 & & $-1,101.78$ \\
\hline Percentiles & & & $-6,359.18$ & 28.3761 \\
\hline $0 \%$ & $-7,292.96$ & $-1,096.02$ & -52.4807 & 223.0423 \\
$10 \%$ & 78.03579 & 131.3542 & $1,121.298$ & 362.3651 \\
$20 \%$ & $1,427.025$ & 334.1462 & $1,994.44$ & 476.3636 \\
$30 \%$ & $2,405.299$ & 475.2629 & $2,711.109$ & 590.9754 \\
$40 \%$ & $3,206.409$ & 595.2693 & $3,435.439$ & 703.757 \\
$50 \%$ & $3,979.723$ & 707.4109 & $4,149.133$ & 823.2351 \\
$60 \%$ & $4,768.484$ & 814.7663 & $4,890.374$ & 958.0105 \\
$70 \%$ & $5,584.139$ & 938.358 & $5,794.906$ & $1,153.432$ \\
$80 \%$ & $6,497.534$ & $1,081.795$ & $7,001.865$ & $2,958.231$ \\
$90 \%$ & $7,819.837$ & $1,279.996$ & $12,712.56$ & \\
$100 \%$ & $14,096.05$ & $2,272.42$ & & \\
\hline
\end{tabular}

$1 \mathrm{US} \$=\mathrm{R} \$ 3.80$ in July, 2018.

good alternative method to analyze the economic scenario of a project of integration of cultures. And it should not be considered as the only and best alternative of analysis, since it works with probabilities of occurrence of variables.

In addition, the idea of high risk should not always be conditioned to a negative feature of the investment, but, as an opportunity to increase the competitiveness of the enterprise [33]. Since traditional methods of analysis do not consider competitive advantage, future opportunities and managerial flexibility (intangible factors) in their methodologies [34], high risk can mean an opportunity to adopt new managerial and productive strategies.

In order to reduce the risks of the enterprise and to adjust the intangible factors in the analyses of financial-economic feasibility and risk, it is suggested to use the real options theory methodology (ROA), which seeks to analyze the viability of the project against future investment opportunities and possible flexibilities inherent in project risk.

\subsection{Sensitivity Analysis}

Considering the scenarios analyzed for variation of the discount rate, productivity and prices, it is possible to observe variations in the ANPV values of the project, as well as variations in the cutting age of eucalyptus.

In scenario I, there was only a change in the cutting age of eucalyptus, when the variable discount rate was changed. In this case, with the increase of the discount rate, the cut age began to occur in the 6th year.

The alteration of the other variables did not lead to any change in the ideal cutting age of eucalyptus. Only changes in the ANPV were verified, as shown in Table 11.

In scenario II, no change in the age of cut was observed, always remaining seven years, with the variations proposed by the sensitivity analysis. As was the case in scenario I, the ANPV underwent changes with the variations, as shown in Table 12.

Studies conducting the sensitivity analysis in eucalyptus plantations also showed that the increase of 
Table 11 Results of the sensitivity analysis for scenario I.

\begin{tabular}{llll}
\hline Variables & Variation & ANPV & Cutting age \\
\hline Discount rate & $\uparrow$ & $\uparrow$ & $\downarrow$ \\
\multirow{2}{*}{ Productivity } & $\uparrow$ & $\uparrow$ & - \\
& $\downarrow$ & $\downarrow$ & - \\
Price & $\uparrow$ & $\uparrow$ & - \\
& $\downarrow$ & $\downarrow$ & - \\
\hline
\end{tabular}

$\uparrow$ and $\downarrow$ indicate increase and decrease of values, respectively.

- indicates that no variation was observed.

Table 12 Results of the sensitivity analysis for scenario II.

\begin{tabular}{llll}
\hline Variables & Variation & ANPV & Cutting age \\
\hline Discount rate & $\uparrow$ & $\downarrow$ & - \\
Productivity & $\uparrow$ & $\uparrow$ & - \\
& $\downarrow$ & $\downarrow$ & - \\
Price & $\uparrow$ & $\uparrow$ & - \\
& $\downarrow$ & $\downarrow$ & - \\
\hline
\end{tabular}

$\uparrow$ and $\downarrow$ indicate increase and decrease of values, respectively.

- indicates that no variation was observed.

the discount rate negatively affects the profitability of the enterprise. This result was expected, since with the increase of the rate, the risk of the enterprise increases and the ANPV tends to decrease. High discount rates tend to make forestry projects unfeasible in the long run [28]. Studies analyzing economic viability of a forest in the Cerrado obtained the same results [35].

In forestry projects, due to the long investment conversion time, the viability of the project has considerable sensitivity to variations in the discount rate and, therefore, it is suggested to use rates lower than those used in other sectors of the economy [35].

The data in Tables 13 and 14 show the simulations on the productivity of the system products, as well as the impact of these variations on the ANPV of the project. Scenario II behaved similarly to scenario I, as shown in Table 14.

None of the simulations made the system unfeasible in both production scenarios. But it is possible to observe that the activities of livestock and forestry were the ones that most impacted the ANPV of the project, in front of the simulations made.

It is possible to conclude that, although influencing the project ANPV differently, the activities are dependent on one another and therefore the system should be evaluated as a whole [20].

The data in Tables 15 and 16 show the simulations on the prices of the crop-livestock-forestry system products, as well as the impact of these variations on the project ANPV. Scenarios I and II behaved similarly in the analysis.

In both scenarios I and II, the simulation performed under pessimistic scope (minimum price found in the historical series of all products) would be unfeasible, with NPV and ANPV less than zero, when the price of cattle was equal to $\mathrm{R} \$ 26.22$.

However, it should be noted that the probability of occurrence of this price of cattle is approximately $4.8 \%$ (value found in the cattle price histogram), i.e., there is a low probability of occurrence of this scenario, the risk is so low.

In general, the minimum prices found in the historical series of product prices have a low probability of occurrence (soybean-4.73\%, maize $-8.89 \%$, eucalyptus- $2 \%$ ), showing that the pessimistic scenarios and lower ANPV generated by low prices have a low probability of occurring.

As observed in the simulations made with product productivities, in the analysis made with price variations, forest and livestock activity also have a greater 
Table 13 Results of the sensitivity analysis varying only the productivity of the crops, in scenario I.

\begin{tabular}{lllllll}
\hline Soy $(\mathrm{sack} / \mathrm{ha})$ & Maize $(\mathrm{sack} / \mathrm{ha})$ & Cattle $(\mathrm{kg} / \mathrm{ha})$ & Eucalyptus $\left(\mathrm{m}^{3} / \mathrm{ha}\right)$ & ANPV $(\mathrm{R} \$ \mathrm{ha})$ & Variation $(\%)$ & Impact on ANPV \\
\hline 36.30 & 67.00 & 18.00 & 186.19 & $1,131.425$ & 3.22 & 3 \\
29.70 & 67.00 & 18.00 & 186.19 & $1,060.759$ & & \\
39.60 & 67.00 & 18.00 & 186.19 & $1,166.758$ & 6.45 & \\
26.40 & 67.00 & 18.00 & 186.19 & $1,025.427$ & & \\
59.77 & 73.70 & 18.00 & 186.19 & $1,123.482$ & 2.50 & \\
59.77 & 60.30 & 18.00 & 186.19 & $1,068.703$ & & \\
59.77 & 80.40 & 18.00 & 186.19 & $1,150.871$ & 5.00 & \\
59.77 & 53.60 & 18.00 & 186.19 & $1,041.313$ & & \\
59.77 & 67.00 & 19.80 & 186.19 & $1,269.082$ & 15.800 & 2 \\
59.77 & 67.00 & 16.20 & 186.19 & 923.102 & & \\
59.77 & 67.00 & 21.60 & 186.19 & $1,442.073$ & 31.600 & \\
59.77 & 67.00 & 14.40 & 186.19 & 750.112 & & \\
59.77 & 67.00 & 18.00 & 204.81 & $1,173.728$ & 7.080 & \\
59.77 & 67.00 & 18.00 & 223.43 & $1,251.363$ & 14.170 & \\
59.77 & 67.00 & 18.00 & 148.95 & 940.822 & & \\
\hline
\end{tabular}

$1 \mathrm{US} \$=\mathrm{R} \$ 3.80$ in July, 2018; 1 sack $=60 \mathrm{~kg}$.

Table 14 Results of the sensitivity analysis varying only the productivity of the crops, in scenario II.

\begin{tabular}{|c|c|c|c|c|c|c|}
\hline Soy (sack/ha) & Maize (sack/ha) & Cattle $(\mathrm{kg} / \mathrm{ha})$ & Eucalyptus (m³/ha) & ANPV (R\$/ha) & Variation $(\%)$ & Impact on ANPV \\
\hline 34.10 & 67.00 & 18.00 & 12.00 & 983.083 & \multirow{2}{*}{3.49} & \multirow{4}{*}{4} \\
\hline 27.90 & 67.00 & 18.00 & 186.19 & 916.700 & & \\
\hline 37.20 & 67.00 & 18.00 & 186.19 & $1,016.274$ & \multirow{2}{*}{6.99} & \\
\hline 24.80 & 67.00 & 18.00 & 186.19 & 883.508 & & \\
\hline 59.77 & 77.00 & 18.00 & 186.19 & 978.507 & \multirow{2}{*}{3.01} & \multirow{4}{*}{3} \\
\hline 59.77 & 63.00 & 18.00 & 186.19 & 921.275 & & \\
\hline 59.77 & 84.00 & 18.00 & 186.19 & $1,007.123$ & \multirow{2}{*}{6.03} & \\
\hline 59.77 & 56.00 & 18.00 & 186.19 & 892.659 & & \\
\hline 59.77 & 67.00 & 19.80 & 186.19 & $1,122.881$ & \multirow{3}{*}{18.210} & \multirow{4}{*}{1} \\
\hline 59.77 & 67.00 & 16.20 & 186.19 & 776.901 & & \\
\hline 59.77 & 67.00 & 21.60 & 186.19 & $1,295.872$ & & \\
\hline 59.77 & 67.00 & 14.40 & 186.19 & 603.911 & 36.420 & \\
\hline 59.77 & 67.00 & 18.00 & 76.81 & $1,015.881$ & \multirow{2}{*}{6.950} & \multirow{4}{*}{2} \\
\hline 59.77 & 67.00 & 18.00 & 62.85 & 883.901 & & \\
\hline 59.77 & 67.00 & 18.00 & 83.80 & $1,164.063$ & \multirow[t]{2}{*}{22.550} & \\
\hline 59.77 & 67.00 & 18.00 & 55.86 & 817.911 & & \\
\hline
\end{tabular}

$1 \mathrm{US} \$=\mathrm{R} \$ 3.80$ in July, 2018; 1 sack $=60 \mathrm{~kg}$.

Table 15 Results of the sensitivity analysis varying only the prices of the products, in scenario $I$.

\begin{tabular}{lllllll}
\hline Soy $(\mathrm{sack} / \mathrm{ha})$ & Maize $(\mathrm{sack} / \mathrm{ha})$ & Cattle $(\mathrm{kg} / \mathrm{ha})$ & Eucalyptus $\left(\mathrm{m}^{3} / \mathrm{ha}\right)$ & ANPV $(\mathrm{R} \$ / \mathrm{ha})$ & Variation $(\%)$ & Impact on ANPV \\
\hline 72.500 & 24.190 & 115.650 & 35.000 & $1,171.345$ & 6.870 & 3 \\
13.850 & 24.190 & 115.650 & 35.000 & 824.638 & 24.770 & \\
59.770 & 30.510 & 115.650 & 35.000 & $1,167.652$ & 6.530 & 4 \\
59.770 & 7.860 & 115.650 & 35.000 & 911.193 & 16.870 & \\
59.770 & 24.190 & 114.800 & 35.000 & $1,083.378$ & 1.160 & 1 \\
59.770 & 24.190 & 26.220 & 35.000 & -241.609 & 122.040 & \\
59.770 & 24.190 & 115.650 & 59.740 & $1,644.863$ & 50.070 & 2 \\
59.770 & 24.190 & 115.650 & 17.410 & 705.919 & 35.600 & \\
\hline
\end{tabular}

$1 \mathrm{US} \$=\mathrm{R} \$ 3.80$ in July, 2018; 1 sack $=60 \mathrm{~kg}$. 
Table 16 Results of the sensitivity analysis varying only the prices of the products, in scenario II.

\begin{tabular}{lllllll}
\hline Soy $(\mathrm{sack} / \mathrm{ha})$ & Maize $(\mathrm{sack} / \mathrm{ha})$ & Cattle $(\mathrm{kg} / \mathrm{ha})$ & Eucalyptus $\left(\mathrm{m}^{3} / \mathrm{ha}\right)$ & ANPV $(\mathrm{R} \$ / \mathrm{ha})$ & Variation $(\%)$ & Impact on ANPV \\
\hline 72.500 & 24.190 & 115.650 & 35.000 & $1,020.583$ & 7.440 & 3 \\
13.850 & 24.190 & 115.650 & 35.000 & 694.889 & 26.850 & \\
59.770 & 30.510 & 115.650 & 35.000 & $1,024.655$ & 7.870 & 4 \\
59.770 & 7.860 & 115.650 & 35.000 & 756.713 & 20.340 & \\
59.770 & 24.190 & 114.800 & 35.000 & 937.177 & 1.340 & 1 \\
59.770 & 24.190 & 26.220 & 35.000 & -387.810 & 140.830 & 2 \\
59.770 & 24.190 & 115.650 & 59.740 & $1,416.346$ & 49.110 & 2 \\
59.770 & 24.190 & 115.650 & 17.410 & $1,416.346$ & 49.110 & \\
\hline
\end{tabular}

$1 \mathrm{US} \$=\mathrm{R} \$ 3.80$ in July, 2018; 1 sack $=60 \mathrm{~kg}$.

influence on the ANPV of the project, that is, the economic viability of the system depends more on these activities than on the activities (soy and maize). Souza et al. [24] found the same results when applying the methodology of sensitivity analysis in an agroforestry in Minas Gerais.

\section{Conclusions}

- The optimal age for eucalyptus was cut to seven, on both, scenario I and scenario II. This result was obtained by both deterministic and probabilistic methods;

- Scenario I had better return on investment on both, deterministic and probabilistic methods;

- Reduction was found in the ANPV indicator for scenarios I and II, respectively, after applying the Monte Carlo method;

- The production of scenario I presents higher investments risks;

- Considering the different possible scenarios for discount rate, it was possible to observe that there is a negative relation between discount rate and ANPV;

- Increased productivity of crops provides greater profitability to the system;

- There has been an increase in the economic viability of the system, as value has been added to the products;

- Even if the various crop-livestock-forestry system cultures impact differently on ANPV and project feasibility (varying productivities and prices), the system must be evaluated as a whole;
- The Monte Carlo method and the sensitivity analysis showed to be an appropriate tool to analyze the risk of crop-livestock-forestry systems, making it possible to foresee how the project will respond to possible scenarios.

\section{References}

[1] Sanguino, A. C., Santana, A. C. de, Homma, A. K. O., Barros, P. L. C. de, Kato, O. K., and Amin, M. M. G. H. 2007. "Economic Analysis of Investments in Agroforestry Production Systems in the State of Pará." Journal Agricultural Sciences 47: 23-47.

[2] Silva, S. C. da. 2012. "Agroforestry in the Amazon: Phytosociology, Socioeconomic, Risk Analysis, Marketing and Price Trend of Products." Ph.D. thesis, Federal University of Lavras.

[3] Balbino, L. C., Cordeiro, L. A. M., Porfírio-Da-Silva, V., Moraes, A. de, Martinez, G. B., Alvarenga, R. C., Kichel, A. N., Fontaneli, R. S., Santos, H. P. dos, Franchini, J. C., and Galerani, P. R. 2011. "Technological Progress and Clusters of Crop-Livestock-Forest Integration Systems in Brazil.” Search Brazilian Agriculture 46 (10): 1-12.

[4] Varela, L. B., and Santana, A. C. de. 2009. "Economic Aspects of Production and the Risk of Agroforestry Systems and Traditional Systems of Agricultural Production in Tomé-Açu, Pará, 2001-2003." Tree Magazine 33 (1): 151-60.

[5] Bulhões, F. M. 2011. "Knowledge and Innovation in the Management of Agroforestry Systems for Ecological Growers in the Vale do Caí." Ph.D. thesis, Federal University of Rio Grande do Sul.

[6] Dawnson, I. K., Guariguata, M. R., Loo, J., Weber, J. C., Lengkekk, A., Bush, D., Cornelius, J., Guarino, L., Kindt, R., Orwa, C., Russel, L., and Jamnadass, R. 2013. "What Is the Relevance of Smallholders' Agroforestry Systems for Conserving Tropical Tree Species and Genetic Diversity in Circa Situm, in Situ and Ex Situ Setting? A 
Review." Biodiversity and Conservation 22 (2): 201-324.

[7] Nerlich, K., Graeff-Honninger, S., and Claupein, W. 2013. "Agroforestry in Europe: A Review of the Disappearance of Traditional Systems and Development of Modern Agroforestry Practices, with Emphasis on Experiences in Germany." Agroforestry Systems 87 (5): 475-92.

[8] International Council of Research in Agroforestry (ICRAF). 1986. An Introduction to Agroforestry Diagnosis and Design. Nairobe: Kluwer Academic Plubishers, 56.

[9] Simioni, F. J., and Hoeflich, V. A. 2006. "Risk Assessment for Forestry Investments.” Brazilian Journal of Forestry Research 52: 79-92.

[10] Cordeiro, S. A. 2010. "Economic Evaluation and Simulation in Agroforestry." Ph.D. thesis, University of the Fraser Valley.

[11] Rezende, J. L. P., Souza, A. N., and Oliveira, A. D. 2001. "Study Time Great Stands of Replacement of Eucalyptus spp.: The Case of Increased Revenue." Scientia Florestalis 59: 27-39.

[12] Campos, J. C. C., and Leite, H. G. 2013. Forest Measurement-Questions and Answers. Lavras: Publisher UFV, 605.

[13] Scolforo, J. R. S. 1998. Forest Management. Lavras: FAEPE/UFLA, 438.

[14] Rezende, J. L. P., and Oliveira, A. D. 2013. Economic and Social Analysis of Forestry Projects. Viçosa: UFV Publishing House, 389.

[15] Joaquim, M. S. 2012. "Real Options Analysis in Investment Analysis in Agroforestry Systems." Ph.D. thesis, Universidade de Brasília.

[16] Fundação Getúlio Vargas (FGV). 2013. General Price Index-Internal Availability, Metodologia. Rio de Janeiro: FGV/IBRE.

[17] Fernandes, C. A. B. A. 2005. "Risk Management in Projects: How to Use Microsoft Excel to Perform the Monte Carlo Simulation.” Pontifical Catholic University of Rio Grande do Sul, http://www.pucrs.br/ciencias/viali/especializa/mia_ima_f afis/material/ead/artigos/MonteCarloExcel.pdf.

[18] Coelho Júnior, L. M., Rezende, J. L. P. de, Coimbra, L. A. B., and Souza, A. N. 2008. "Investment Analysis of an Agroforestry System under Risk." Cerne 14 (4): 368-78.

[19] Silva, W. C., and Cunha, A. C. 2013. "The Use of Risk Analysis in the Study of Economic Viability and Compensation for Carbon Credits in Family Farming System.” Biota Amazon 3 (2): 101-15.

[20] Souza, A. N. de. 2005. "Growth, Yield and Economic Analysis of Clonal Stands of Eucalyptus sp. in Agroforestry Systems." Ph.D. thesis, Universidade Federal de Lavras.

[21] Souza, A. N. de, Oliveira, A. D. de, and Rezende, J. L. P. de. 2001. "Great Moment of Replacement Stands of Eucalyptus spp. The Case of Constant Technology." Cerne 7 (2): 93-104.

[22] Richetti, A. 2012. Economic Viability of the Soybean Crop in 2012/2013 Crop in Mato Grosso do Sul. Dourados: Embrapa Agropecuaria Oeste, 9.

[23] Amaro, G. C. 2010. "Modeling and Simulation of Economic Agroforestry in the Brazilian Amazon." Master thesis, Federal University of Rio Grande do Sul.

[24] Souza, A. N. de, Oliveira, A. D. de, Scolforo, J. R. S., Rezende, J. L. P. de, and Mello, J. M. 2007. "Economic Feasibility of an Agroforestry System." Cerne 13 (1): 96-106.

[25] Arco-Verde, M. F. 2008. "Biophysical and Socio-Economic Sustainability of Agroforestry in the Brazilian Amazon.” Ph.D. thesis, Federal University of Paraná.

[26] Bramucci, M. 2001. "Determination and Quantification of Influence Factors on the Productivity of 'Harvesters' in Wood Harvesting." Master's thesis, Escola Superior de Agricultura Luiz de Queiroz.

[27] Dias, A. N., Leite, H. G., Silva, M. L. de, and Carvalho, A. F. de. 2005. "Economic Evaluation of Eucalyptus Plantation Submitted to Thinning." Tree Magazine 29 (3): 419-29.

[28] Rezende, J. L. P., and Oliveira, A. D. 1994. "Relations between the Age of Cutting and Planning Horizon, in Eucalyptus Stands." Cerne 1 (1): 95-107.

[29] Soares, T. S., Silva, M. L. de, Gama, J. R. V., Carvalho, R. M. M. A., and Vale, R. S. de. 2003. "Economic Evaluation of Eucalyptus Plantation Submitted to Thinning." Tree Magazine 27 (7): 481-6.

[30] Wilcken, C. F., Lima, A. C. V., Dias, T. K. R., Masson, M. V., Ferreira Filho, P. J., and Dal Pagetto, M. H. F. A. 2008. Practical Management of Eucalyptus Plantations Guide. FEPAF-UNESP.

[31] Premono, B. T., and Lestari, S. 2018. "Financial Analysis on Agroforestry System of Coffee with Marrango Tree (Azadirachta excelsa Jack.) in Rejang Lebong Regency, Bengkulu Province, Indonesia." Indonesian Journal of Forestry Research 5 (1): 45-56.

[32] Tsonka, P., Mirk, J., and Futz, B. 2018. “Addressing Farmer-Perceptions and Legal Constraints to Promote Agroforestry in Germany.” Agroforestry Systems 92 (4): 1091-103.

[33] Nardelli, P. M., and Macedo, M. A. S. 2011. "Analysis of an Agribusiness Project Using the Real Options Theory: Deferral Options." Journal of Economics and Rural Sociology, Piracicaba 49 (4): 941-66.

[34] Santos, E. M., and Pamplona, E. O. 2005. "Theory of Real Options: An Attractive Option in the Process of Analyzing Investments.” Magazine Management, São 
Paulo 40 (3): 235-52.

[35] Oliveira, D. de O., Leite, A. P., Botelho, S. A., and Scolforo, J. R. S. 1998. "Economic Evaluation of the
Cerrado Vegetation under Different Management Regimes and Eucalyptus Plantations Planted in Monoculture." Cerne 4 (1): 34-56. 